How Lean transforms relationships to empower employees and increase impact

DR ANDREW PARRIS AND DR BUBLU THAKUR-WEIGOLD

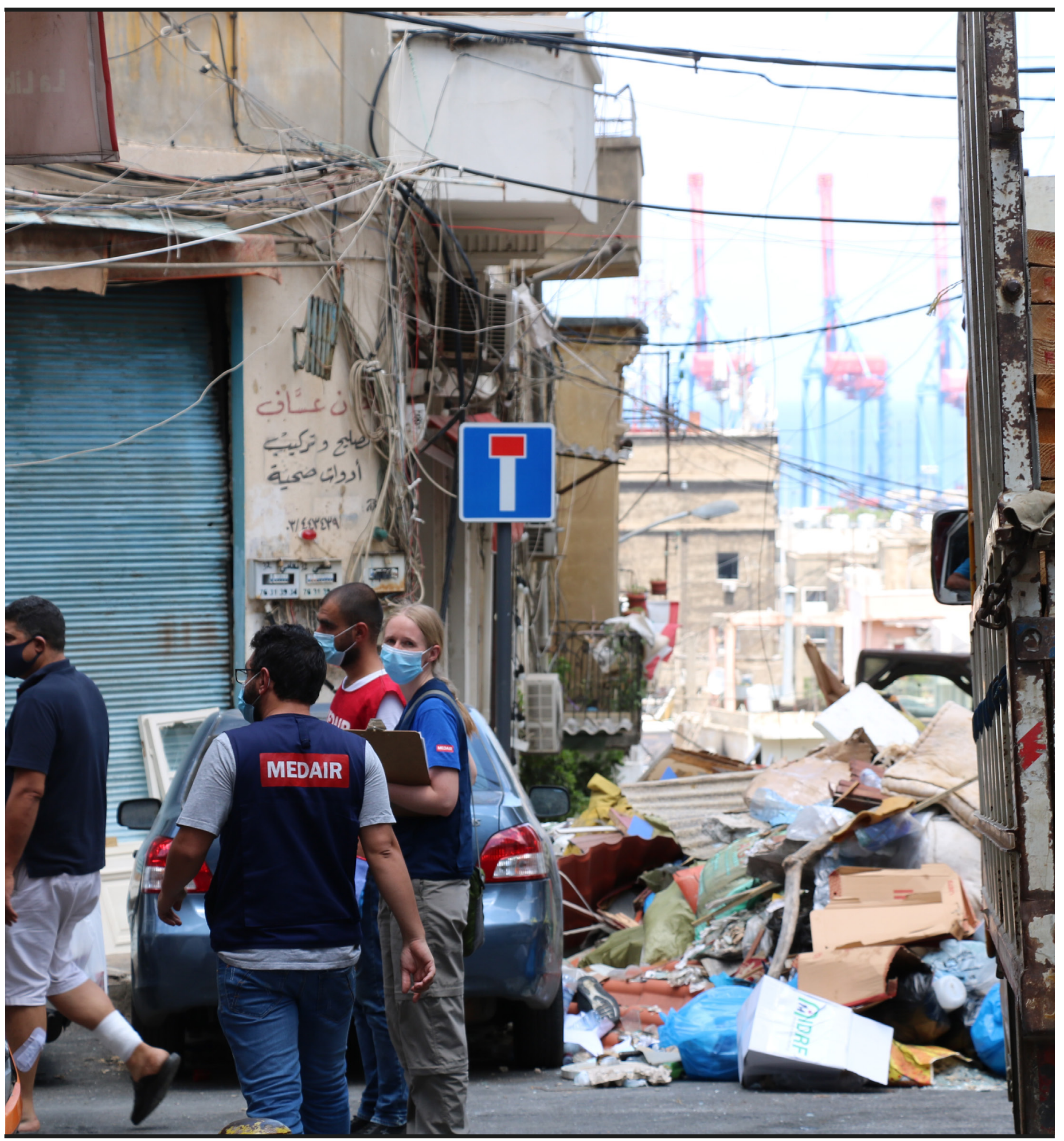




\section{THE HUMANITARIAN LEADER: \\ How Lean transforms relationships to empower \\ employees and increase impact}

\section{WORKING PAPER 019}

OCTOBER 2021

\section{Author Details}

\section{Dr Andrew Parris and Dr Bublu Thakur-Weigold}

Dr Bublu Thakur-Weigold is Associate Director of the HumOSCM Lab at ETH Zurich's Chair of Logistics Management. Dr Andrew Parris is the Process Excellence Manager at Medair. Both are graduates of the Massachusetts Institute of Technology

\section{Acknowledgements}

The authors thank the panel participants Abebe Nigatu of World Vision, Darine Ndihokubwayo of Food for the Hungry, Elias Yacoub of Medair, and Robert Ssaka of the Government of Uganda. They also acknowledge a growing number of humanitarian workers, some of whom they know, and others they have never met, all of whom work tirelessly and with great effect, to apply Lean in the non-profit sector. These colleagues are increasing the impact of humanitarian work to reach more people in need, while empowering their teams to be more creative and productive. Special thanks are extended to Lysann Seifert for the transcription of the panel recording.

\section{Editorial Office}

The Centre For Humanitarian Leadership

Deakin University

221 Burwood Highway

Burwood 3125 VIC

Australia

Editor in Chief: Dr Nazanin Zadeh-Cummings

ISSN: 2653-1011 (Online)

The Humanitarian Leader is made possible by support from the IKEA foundation.

The Centre for Humanitarian Leadership acknowledges the Australian Aboriginal and Torres Strait Islander peoples of this nation. We acknowledge the traditional custodians of the lands on which we work. We pay our respects to ancestors and Elders, past and present.

\section{Copyright}

This paper was prepared for the Centre for Humanitarian Leadership. The views expressed herein are those of the authors and do not necessarily reflect the views of the Centre for Humanitarian Leadership. These papers are circulated for discussion and comment purposes. They have not been peer reviewed.

() 2021 by Dr Andrew Parris and Dr Bublu Thakur-Weigold. All rights reserved.

Cover image: A Medair team distributes 'sealing off' kits to affected families in Beirut in the aftermath of the Beirut port explosion of August 2020. @ Medair/Hiba Hajj Omar 


\section{Abstract}

The challenges of humanitarian leadership are well-studied by the social sciences. However, there is untapped potential in applying private sector management principles and best practices to humanitarian work. Some nonprofit organisations have fruitful experience applying Lean Management, an innovative management system developed by Toyota, which is not just about manufacturing better cars or improving industrial processes. Lean focuses the organisation on providing more value to its customers which, in the case of the humanitarian sector, are its beneficiaries. Our panel shared their experience of using Lean Management to address common issues in humanitarian operations. Their stories demonstrate the potential of Lean to transform work and relationships by devolving power to lower-level workers and partners. By empowering staff and local entities, it also improves relationships, collaboration, and ultimately the outcomes of humanitarian missions.

\section{Leadership relevance}

We argue that Lean Management is the practice of leadership from the ground up, driving an internal transformation that produces strategic gains. While doing so, it aligns with the principles and values of humanitarian work and could help to reduce imbalances of power. 


\section{Introduction}

This paper, based on a panel presentation at the 2021 Humanitarian Leadership Conference, presents evidence of how Lean Management principles can empower employees and improve the impact of humanitarian work.

When we think of emergency response or humanitarian aid, it is widely assumed that a combination of good intentions, political will, and adequate funding will lead to meaningful results. By the same logic, perceived shortfalls in real performance are attributed to corruption, excessive overhead, or bureaucratic incompetence (usually without evidence). These assumptions deserve closer scrutiny. In the face of growing humanitarian need around the world, stepping up the pressure on individuals or institutions to donate more is not automatically the best answer, and certainly not the only answer. Without improving the system of work, its processes and how people contribute, simply pumping more inputs into that system will not improve beneficiary impact. An exclusive focus on governance (intensifying controls and audits), or spot innovations like drones or Geographic Information System (GIS) applications, will not suffice either. In our experience, operational excellence is one of the most sustainable solutions to shrinking donor budgets and the increasing funding gap.

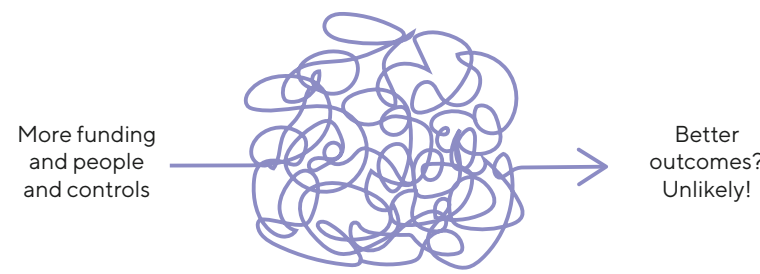

Figure 1: Simply pumping more inputs into a wasteful and dysfunctional system will not improve beneficiary impact.

In our experience, operational excellence is one of the most sustainable solutions to shrinking donor budgets and the increasing funding gap.

To demonstrate this, our panellists discussed how each of their organisations applied Lean Management to their work. Commercial organisations originally developed Lean Management because they, like their humanitarian counterparts, were also under pressure to use their resources judiciously, and to deliver measurable benefits. Over decades of practice, Lean has enabled private sector companies to 'do more with less', increasing both efficiency (defined as optimal use of resources, often reducing cost), and effectiveness (defined as achieving declared objectives). Humanitarian missions clearly need these kinds of improvements as well.
What makes Lean even more interesting to the humanitarian sector are the long-term cultural changes that take place within a Lean organisation: dismantling hierarchical command-and-control structures, devolving power to decision-makers on the front lines, team-based problem-solving, and empowering national staff. Based on the evidence, we are convinced that Lean can reduce imbalances of power.

Commercial organisations originally developed Lean Management because they, like their humanitarian counterparts, were also under pressure to use their resources judiciously, and to deliver measurable benefits.

In the following sections, we will explain what Lean is, describe how it was applied to four cases in the field, and provide a simple framework to help organisations to begin applying it themselves.

\section{What is Lean and why is it important for humanitarian leadership?}

Lean is a form of team-based continuous improvement focusing on the identification and elimination of nonvalue-added activities, also known as 'waste', from the point of view of the customer (Myerson in Netland \& Powell 2017; 413).

To begin with the basics, Lean is a management system developed in the auto industry. After the devastation of the war, Toyota was a humble maker of industrial looms that made the quixotic decision to build cars. With very few resources and experience, located in an economically ravaged country, the Asian firm was an unlikely challenger to the prosperous Western manufacturers that dominated the world at the time. Ford Motor Company had invented not only the car, but the production process (the assembly line), that made its output both profitable and accessible to mass markets. Against the odds, and in the course of a few decades, Toyota was able to exceed the performance of its mighty competitors. Today, it is generally acknowledged by industry and academia that the Toyota Production System, also known as Lean Management, was the enabler of this success (Womack et al. 1991). Closely associated with Lean is Six Sigma, which was invented at the Motorola company, and made famous by Jack Welch at GE corporation. Six Sigma is a method to improve industrial processes and business performance by reducing variability.

At first glance, a methodology to improve factory performance may not appear relevant to humanitarians. "We are helping people, not making widgets", is a dismissive reaction we often hear from humanitarian leaders. However, the Cinderella story of the Toyota 
company illustrates the extraordinary potential that Lean, with its emphasis on continuous improvement, can have on any and every organisation.

\section{However, the Cinderella story of the Toyota company illustrates the extraordinary potential that Lean, with its emphasis on continuous improvement, can have on any and every organisation.}

At a practical level, Lean is based on the idea that organisations can add more value to their customersin the case of humanitarian work, the beneficiaries they serve-by continuously improving everything they do by, for example, eliminating waste, finding ways to prevent mistakes, and by making it easier to see where problems routinely occur. Lean relies on the people working in the system to quickly solve problems at their root cause. Lean is, therefore, an alternative to the conventional hierarchical systems of command and control, which assumes that the boss knows best and should therefore make all key decisions, which are handed down to the less capable staff for (more or less mindless) execution.

Lean relies on the people working in the system to quickly solve problems at their root cause.

Lean can also be seen as a way to make work easier, faster, and cheaper so that resources go further and achieve greater impact. Although it is now associated with a set of tools (like just-in-time manufacturing, or Kanban), Lean is actually a way of thinking founded on respect for people, which is a fundamental value in humanitarian organisations. Lean builds the capacity of staff and then draws on their experience and insight to make processes better. It treats every employee's time, energy and ideas as precious resources that should not be wasted. Lean also reduces the burden on people caused by poor quality workflows, delays and excessive workload-common realities in humanitarian work that reduce well-being and may eventually lead to resignation.

Lean is best illustrated by real life examples that the panel presented. For example:

- Mapping and streamlining of processes, such as a procurement process from sourcing to payments, so everything happens more quickly and correctly

- Creating a standard operating procedure for shipping that identifies all the steps that need to be taken, to make sure that they're not missed, so that goods move to where they are needed as quickly as possible
- Preparing all required documents in advance of receiving goods in customs, so that the paperwork is submitted in a timely manner and the delivery leaves the airport as quickly as possible to reach beneficiaries

- Even labelling the cabinets visually in a shared kitchen so new staff can immediately see where things are, rather than having to open every cabinet to find what they need.

The immense success of Lean management relies on a deceptively simple accumulation of incremental improvements made by individuals and teams that learn to solve problems together. The shared satisfaction of doing things right and taking pride in being productive cannot be overstated, since it sets expectations of excellence in an organisation. Lean Management has established itself as a global standard, which has been applied to many contexts beyond the car factory, including service and non-profit sectors (Lean Education, Lean Healthcare and more). In spite of the ongoing professionalisation in the humanitarian sector, Lean has not, however, had the influence in this area that its track record would justify. It is this gap that motivates our research and this article.

\section{The panel}

Given the low profile of industrial solutions among humanitarian decision-makers, the sector's strong emphasis on political and social agency, and the often-formulaic documentation of Lean Programs at practicing firms, we felt that personal testimony would be the most compelling way to diffuse this innovation. To this end, we convened a panel consisting of five managers from international humanitarian organisations or government agencies.

1. Abebe Nigatu Endalew, People and Culture Director, World Vision Rwanda

2. Dr Andrew Parris, Process Excellence Manager, Medair Switzerland

3. Darine Ndihokubwayo, Commodity Manager, Food for the Hungry Democratic Republic of the Congo (DRC)

4. Elias Yacoub, Logistics and Security Manager, Medair Lebanon

5. Robert Ssaka, Project Manager, Integrated Personnel and Payroll System, Ministry of Public Service, Government of Uganda Kampala

Dr Bublu Thakur-Weigold, the Director of the HumOSCM Lab at the Swiss Federal Institute of Technology (ETH) Zurich, and one of the authors of this paper, moderated the discussion.

The other author, Dr Andrew Parris, a long-time advocate of Lean, started with Lean in his doctoral studies in mechanical engineering at the Massachusetts Institute of Technology, where the seminal study of the Toyota Production System (TPS) was made (Womack et al 1991). His research team, Lean Aircraft Initiative, studied the possibility of applying Lean to businesses outside of automobile manufacturing. They discovered 
that the transfer was not only feasible, but that Lean could greatly benefit the aircraft industry, which it was already starting to do. With this lesson in mind, Andrew gained practical experience with Lean management at Lockheed Martin before bringing Lean into the development and humanitarian sectors (Parris 2013, 2019, 2020). He applied Lean Six Sigma for nine years at World Vision, three of which were spent in East Africa, delivering training and supporting improvement. Andrew, who now promotes Lean in Medair as well as at other NGOs, trained all the panellists. The following case studies are summaries of their presentations at the conference session.

\section{Case studies and learning}

\section{Robert's story: accelerating government payroll operations in Uganda}

For many governments, including the government of Uganda, Lean is a new thing. They have not thought about using Lean and the benefits that are proven in industry. Having come from a background of Lean in the NGO sector, Robert saw an opportunity to use it to transform employee relations, productivity, and process efficiency for government operations and, in particular, the process of retirement benefits. It originally took an average of 2.8 years for the government of Uganda to start paying out retirement benefits to their employees after they retired. This lengthy delay created frustration and contributed to low levels of motivation among working government employees, who were aware that some of them would die before ever accessing their pensions

By leveraging Lean practices, the team came up with a way to improve the situation, which not only impacted employee productivity, but also improved the image of the government as a provider of quality and reliable services. Robert's colleagues mapped out the business process, looked at the underlying issues affecting the information needed for the process to start, and who had access to this information. They identified the roles and responsibilities, and made sure that there were rules for decision-making. And at the end of the day, they were able to identify the pain points in the process that led one department to take one year to process the pension application, while another finished in five years. These delays occurred even when the government had allocated money to pay employees as they retired.

The government of Uganda is a complex structure, with more than 80 local bodies operating all over the country. This meant that every problem in the regions eventually had to try to come to Kampala. The project therefore solved a number of logistics challenges that caused delays. In so doing, they decentralised the service, which helped to empower employees and restore the trust lost by retirees. Most importantly, the government was able to effectively use this success as a domestic example of positive change. At the same time, they experienced improved working relationships, higher employee productivity, and a happier community.

By making the workflow visible, working together to streamline it and reduce the number of handoffs, Robert Ssaka's Lean team was able to reduce pension applications from three years to five days.

To summarise, Robert's Lean project solved a problem in government operations in which pension payments were first made almost three years after the employee left the service of the government. By making the workflow visible, working together to streamline it and reduce the number of handoffs, his Lean team was able to reduce it from three years to five days. This was through simple, logical changes in the process, without any major reorganisation of the government or downsizing, or a new IT system. Indeed, even as Lean came into place, there was no replacement of staff and no one lost their jobs. But at the same time, it simplified the task, and what everybody had to do was clear. According to Robert, "with Lean you can achieve much more with existing resources".

"With Lean you can achieve much more with existing resources."-Robert Ssaka

\section{Darine's story: streamlining purchase-to-pay at}

\section{World Vision in Burundi}

When she began applying Lean, Darine was working with World Vision as a supply chain and administration manager, where the Lean system was virtually unknown. Her team was executing its procurement as it had always been done, according to standard operating procedures and policies. This work proved to be increasingly ineffective and stressful. The system had reached a point where delays in meeting the program's demands and paying suppliers were on the rise. The team faced fraud audit queries and increasing pressure. Darine reflects on the hectic atmosphere in the office, "running up and down purchasing one thing today, tomorrow another... by the way, I need a pen as well". As a result, staff didn't have time to take their leave days, and there was a lot of burnout.

In training with Andrew Parris, Darine was introduced to Lean and Six Sigma, which equipped and inspired Darine to undertake a number of improvement projects. One of these was called Plan-to-Procure-to-Pay, for which Darine was the designated project manager, supported by the country director and other staff. Her team analysed the processes and work, where they discovered that they had been wasting a lot of resources, time, and 
energy. A number of redundancies became apparent. For example, a certain document had to be signed by four or five people in the same department or from the field. A driver had to travel 200 kilometres to get a purchasing requisition approved (signed), incurring costs for fuel and hotels, during which time that driver could not provide other services.

The team analysed what could be done better, changed, or eliminated completely. Darine and her colleagues mapped the processes and submitted a full report of recommended improvements, flagging the time and money that were wasted by the current way of doing things. The management reviewed and approved the proposed changes, and the project team began to implement the plan. They put in place a framework agreement, conducted market surveys to update price lists, and worked with the IT team to automate what was paper based at the time. Later, they presented their solutions to other offices to encourage the adoption of the streamlined processes and analysis of their procurement systems.

Sharing real-life examples from the field, Darine explained how trust erodes when processes are not optimal and a system is set up to fail, which creates a 'blame game'. She noted that when a project was overspent, her colleagues used to automatically blame procurement. The Lean analyses had revealed that they had been purchasing materials for projects that were already in their warehouse. The root cause of avoidable overspend was the organisation's inability to control the stock of items on hand. As a result of overspending, the donor did not trust the organisation, which had to submit to an increasing number of time-consuming audits. The procurement team often had to defend why a particular document was approved on a date that was different from when things were dispatched. They often had no explanation because they had simply reacted to a situation in which someone would bring documents for approval and subsequently lose those documents. A replacement would be prepared and backdated, which raised suspicion. It is also possible that someone with bad intentions executed an unauthorised transaction because it was paper-based, and it was easy to pencil in dates. Darine and her team also realised that they didn't have all the people who were authorised to sign located in one place. Once they became visible, each of these procedural issues were resolved.

Another important challenge faced by the procurement team was the fact that its suppliers typically waited an entire year to be paid. From a business perspective, this type of delay is unacceptable to firms that have delivered goods or services, because it forces them to effectively finance their customers' consumption for over a year. The team diagnosed root causes ranging from the loss of the procurement document, a missing signature, or a procedural enquiry that had not been properly completed.

Darine's Lean pilot project saved USD\$140,000 and reduced the construction time by $50 \%$. Today, World Vision Burundi has a very good relationship with its suppliers, having cut standard payment times from one year to seven days.
Darine's Lean pilot project saved USD\$140,000 and reduced the construction time by $50 \%$. Today, World Vision Burundi has a very good relationship with its suppliers, having cut standard payment times from one year to seven days.

\section{Elias' story: improving emergency response at Medair in Lebanon}

In August 2020, Lebanon faced not only the Beirut blast, a huge chemical explosion, but also lockdown because of Covid-19. The country had a high inflation rate, and the situation was difficult in general. Lebanon relies on imports, and the import prices were affected by the prevailing economic crisis. Because the import currency is USD and Lebanon suffered a shortage of hard currency, this resulted in a shortage of vital goods in the country. This is the context of the Medair emergency response to the Beirut blast.

After the explosion, it took several hours for Medair's emergency team to know what exactly had happened. Senior leaders began to meet to decide how to respond. The first needs assessment, which was done door to door, gave a clearer idea of the needs. The response was divided into two phases, the first of which was the distribution of emergency relief shelter kits, and the second, reconstruction. As in any emergency response, time is of the essence, so Medair's teams quickly began to execute, and adjusted their processes as needed. This is where the existing Lean culture and habits of continuous improvement enabled them to face the daunting task.

\section{As in any emergency response, time is of the essence, so Medair's teams quickly began to execute, and adjusted their processes as needed. This is where the existing Lean culture and habits of continuous improvement enabled them to face the daunting task.}

Knowing there was a lack of materials in the country, Medair started the preparation for the second phase (reconstruction), while the first phase (emergency relief) was ongoing. Elias' logistics team launched a second assessment, using a survey that could be filled in on mobile devices. At the same time, their back office selected three suppliers through an open bid process. They soon realised the standard procurement process was too long and adjustments would have to be made in order to reach beneficiaries as soon as possible. Suppliers were asked to disclose the materials they had in stock, especially the critical quantities of glass 
that were needed to repair shattered windows, but not produced in Lebanon. In addition to inventory availability, they verified potential delivery times.

Elias explained the relentless focus on both incremental and larger process innovations in Medair's response. During the first needs assessment carried out doorto-door, they immediately started improving their method. This involved not only the field team but also the administration and cross-functional staff supporting the assessment. All colleagues reviewed and adjusted their work to the unfolding situation on a daily-if not hourly-basis, which was made possible by entrenched habits of communication. By eliminating the waste in the standard assessment which had been developed in another context, the responders were able to save time, and distribute a substantially larger number of kits than other organisations on the ground at the time (Parris et al. 2021).

Elias emphasised the importance of information-sharing and coordination in an emergency response, where the risk of confusion and redundant work is high. The Medair team worked with low technology like a WhatsApp group that included both volunteers and staff. This simple tool allowed requests coming from the field to go directly to the right person without having to go through the senior management team. In this way, everyone knew what was going on in the field and issues were sorted out by the team on the spot. Elias recalls that they did not wait for orders from the boss. The WhatsApp chat was simultaneously used like a good report, providing a summary of the day's events. Senior management was always informed of these developments, but did not provide detailed instructions on how to respond to each change. These decisions were made by those who were close to the action and understood the conditions on the ground. Collaboration and fast information-sharing is part of the culture that already existed in Medair's Lebanese team, and a source of their high motivation. The country director was in the field on a daily basis to encourage and empower his staff. As Elias noted, "at some points you need motivation to continue, and I was getting it on a daily basis, and I was transferring it to the staff".

\section{Abebe's story: making hiring faster at World Vision in Ethiopia}

Without the right staff in the field at the right time, humanitarian missions cannot be successful. Abebe's organisation struggled with a recruitment process that was long and time-consuming, complex and expensive: before Lean, hiring took 120 days and required 129 work steps to be completed. They understood that this negative performance in a core function was a liability.

Before Lean, hiring took 120 days and required 129 work steps to be completed.
The philosophy of Lean encouraged Abebe's team to investigate the root causes of the dysfunction. They uncovered an excessive number of work steps and decision points in the process. After agreeing upon a common vision of excellence, they proceeded to reduce the process steps, and decision points, which decentralised decision-making. All this required a change of policies and guidelines, as well as the redesigning of approval levels and templates to eliminate the waste. The result was a new recruitment process that, from start to end took about 42 days. After implementing Lean, they had to complete only 60 steps for a new hire. Decision-making points fell from ten to four, making it possible to attract and hire competent and highly skilled candidates from the market in a timely manner.

Abebe reflected on the changes in culture and paradigm shifts that resulted from the project: where previously they had defined processes in their own interests, and through their own eyes, the team learned to see their processes through the customer's eyes. As he explained, "the children we serve are our customers, as are our donors".

Abebe emphasised that in Lean thinking, leaders are not there to improve processes. The people who do the work are there to improve processes, which is the essence of employee empowerment. With Lean they train and mentor employees to be process improvers by themselves. Engaging the entire workforce was very important to their success since organisational performance is not about expert knowledge. According to Abebe, "We don't need experts to come and solve problems. It has to become a place where all staff are engaged in process improvement so that continuous improvement will be a culture".

"We don't need experts to come and solve problems. It has to become a place where all staff are engaged in process improvement so that continuous improvement will be a culture". -Abebe Nigatu Endalew

\section{Lean and humanitarian leadership}

This article raises the voices of industrial engineers as contributors to the discourse on the future of aid, which is dominated by the social sciences, and, arguably, the media. When engineers address the challenges of leadership, the focus of discourse shifts from political action to the drivers of operational performance, which is not commonly associated with strategic change. We argue, however, that Lean is about leadership from the ground up. This type of leadership drives an internal transformation that produces strategic gains (doing more with less which can close the funding gap). While doing so, it aligns seamlessly with the principles and values of humanitarian work. 
As Darine observed, her colleagues at World Vision were initially reluctant to try Lean, thinking that they could not apply anything from the industrial or manufacturing world and expect it to work in a humanitarian setting. But she soon understood that her customers were the beneficiaries they served, and that they deserved to have better services because the donors give humanitarian organisations money to serve these beneficiaries. In her words, her organisation was a channel to convey the money to the beneficiaries. She reflected, "Whenever we give them poor services, whenever our projects fail, we have failed the beneficiaries. They may not be able to talk directly to the donor, but there are evaluations and feedback mechanisms in place. We get to know how a certain organisation is performing".

The stories shared by the panellists illustrate how, over time, any organisation can descend into a downward spiral: when things don't work, people think they can't work. As a consequence, they lose pride and confidence in themselves, and their leaders lose trust in the teams, hence try to control them. The cases demonstrate how, through Lean and continuous improvement, the teams on the ground took control of their system, instead of their system controlling them, and embarked on an upward spiral of performance. By improving one small process segment, the knock-on effects created improvements in other areas. This is how Darine's procurement team proceeded until it had saved USD\$140,000, reduced construction time by $50 \%$, improved donor trust and audit results and, not least, compelled the staff to continue improving their own system. The pride in their achievements is palpable because, although they initially worked with an expert, the crucial knowledge came from within the organisation. It was not Dr Andrew Parris with his MIT pedigree who told the team what to do, but Darine and her colleagues-the experts in their work-who went about devising, implementing, and owning the solutions.

It was not Dr Andrew Parris with his MIT pedigree who told the team what to do, but Darine and her colleagues-the experts in their work-who went about devising, implementing, and owning the solutions.

The results of the individual Lean projects speak for themselves. It is worth emphasising that, although it operates under specific conditions and challenges, the humanitarian sector is not proven to be any more wasteful than commercial industrial systems. On the contrary, a volume of research and case studies affirm that for-profit firms experience similar savings and improvements as they become Lean.

Practitioners of Lean often compare it (somewhat poetically) to a journey, which emphasises the ongoing or open-ended nature of the initiative, and hints at the personal investment. Because systems are characterised by constant change, in both boundary and internal conditions, what is a solution today will become tomorrow's outdated legacy, and a potential source of waste. Sustainable excellence is only possible if attention is paid to updating how work is done, eliminating waste as it becomes apparent, and if the focus on customer/ beneficiary value is relentlessly reinforced.

Because systems are characterised by constant change... what is a solution today will become tomorrow's outdated legacy, and a potential source of waste.

Our panellists made clear that, with basic training and tools, humanitarian workers can apply Lean thinking and tools to achieve more with existing resources. Most readers will also be familiar with the blame game, and the firefighting which is all too common in dysfunctional systems. These are hidden costs in poorly executed humanitarian missions. The capacity-building that occurred in each Lean project also demonstrates the long-term, strengthening effects of continuous improvement on employee empowerment, morale, and a productive work culture. One of the insights gained from our case study of Medair's response to the Beirut Blast (Parris et al 2021), was that the organisation was prepared for that emergency not because it had a detailed 'Urban Explosion Response Plan' in place at any point in time. Instead, their superior results-faster, more effective, and less wasteful-can be attributed to the fact that their people, processes, and technology were mature and high-performing (Garvin 1993). When they took the initiative to respond to the suddenonset crisis, they were quickly able to resolve the emerging challenges on the spot. The benefits of Lean are particularly valuable in high-stress situations and resource-poor environments like these, which is exactly how Toyota began its own journey. 


\section{What your organisation can do to begin with Lean}

Every organisation can begin applying Lean Management principles by following these steps:

1. Learn about Lean (see resources listed below), teach your team, and coach them to apply it.

- Tip: Find a Lean expert to teach and coach you.

2. Start making small improvements on wasteful things that bother you. Structure your projects by following Deming's Plan-Do-Check-Act (PDCA) cycle (see Figure 2)

3. For improvements that affect and need to involve others, convene a team that includes those who do the work. Apply the PDCA cycle together in a rigorous manner.

- Tip: Ensure you identify and address root causes. Do not blame people but focus on what in the structure is creating negative behaviours.

- Tip: Measure the 'before' and 'after' states in the process you are addressing. Document and share what was improved, together with what was learned, ideally using easy-to-digest media like video.
4. Leaders should ask their teams the following three questions about the system of work:

- What is causing problems?

- How can we do this better?

- What do you need to succeed?

....and then apply the PDCA cycle to address what you hear from your people.

5. Study the seven key Lean practices:

- Identify value and waste

- Prevent mistakes

- Organise the area

- Standardise work

- Make work visual

- Make work flow

- Solve problems

...and apply them diligently to improve work

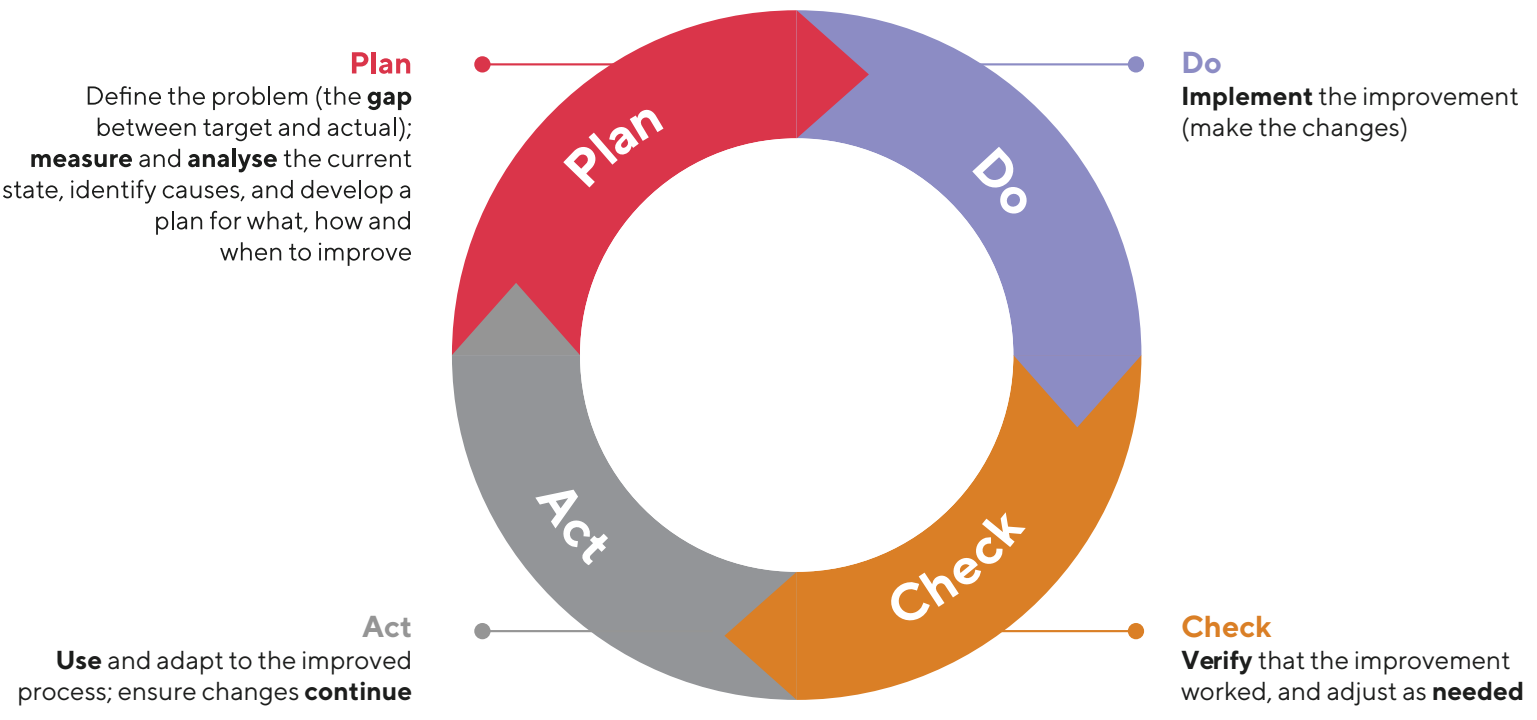


There are many valuable resources available for an individual or organisation wanting to learn more about Lean and apply it in the workplace. Many organisations and experts offer paid conferences, training and workshops. They also provide free resources like newsletters, podcasts, webinars and even electronic books.

Consider the following for starters:

Websites and books:

- Paul Akers (great videos) and his free book 2 Second Lean

- Lean Six Sigma for Good (great stories and e-books)

Blogs and Podcasts

- Gemba Academy (podcast)

- Mark Graban's Lean Blog (podcast)

- The Lean Effect podcast

- Lean Leadership for Ops Managers podcast
Lean Institutes

- Based in the US: Lean Enterprise Institute and their newsletter Lean Post

- Globally: Lean Global Network and their newsletter Planet Lean

Webinars

- Lean Frontiers has some great free webinars

Video from Toyota

- Meals per Hour project helping the Food Bank for New York City

Formal Training and Certification

- The Council for Six Sigma Certification: free PDF Lean Six Sigma textbooks and paid certification exams

Community on LinkedIn

- Lean Thinking for NGOs and Nonprofits: Lean4NGO 
References and recommended reading

Akers, P. A. (2016). 2 Second Lean: How to Grow People and Build a Fun Lean Culture. BookBaby. https://paulakers.net/ books/2-second-lean

Garvin, D. A. (1993). Building a learning organization. Harvard Business Review, 71(4) 78-91.

Girardin, C. (2021). Evaluating the Promotion of Innovation in NGOs. HUMLOG blog. https://blogs.hanken.fi/ humlog/2021/07/28/evaluating-the-promotion-of-innovation-in-ngos/

Netland, T. H., \& Powell, D. J. (Eds.). (2016). The Routledge companion to Lean Management. Taylor \& Francis.

Parris, A. (2013). Improving processes for good in East Africa The TQM Journal. 25(5) 458-472. https://www.wvi. org/sites/default/files/Improving\%20processes\%2Ofor\%2Ogood\%2Oin\%20East\%20Africa.Final\%2Oto\%20 share.2013-08-29.pdf or https://www.linkedin.com/in/andrew-parris-Ob4ab28/detail/overlay-view/urn:li:fsd_ profileTreasuryMedia:(ACoAAAGWAQgBKTHUCM4OmDiR7bcb4tIDLMaoOsc,1554731606281)/.

Parris, A. (2019). Making work and the world a better place. ISE Magazine 51(4) https:// www.linkedin.com/in/andrew-parris-Ob4ab28/detail/overlay-view/urn:li:fsd_ profileTreasuryMedia:(ACoAAAGWAQgBKTHUCM4OmDiR7bcb4tIDLMaoOsc,1554730618048)/.

Parris, A., Pope, D. (2020). What Christian Leaders Can Learn From Lean. Management Sciences. 21. https:// digitalcommons.acu.edu/mgt_sciences/21 or https://www.yumpu.com/en/document/read/64438356/christianbusiness-review-2020-leadership/26.

Parris, A., Thakur-Weigold, B., Wagner, S. (2021). Medair's Beirut Blast Response 2020. unpublished teaching case study. Taylor, D., \& Pettit, S. (2009). A consideration of the relevance of lean supply chain concepts for humanitarian aid provision. International Journal of Services Technology and Management, 12(4) 430-444.

Womack, J. P., Jones, D. T., Roos, D., \& Carpenter, D. S. (1991). The machine that changed the world: based on the Massachusetts Institute of Technology 5-million-dollar 5-year study on the future of the automobile. Rawson Associates. 